\title{
Migrant images: aesthetic imagination in experiences of displacement
}

Original Study

Monica Toledo Silva

Post Graduation Programe in Humanities, Rights and Other Legitimacies-Diversitas daFaculdade de Filosofia, Letras e Ciênc as Humanas da Universidade de São Paulo (PPGHDL, FFLCH, USP); Post Graduation course History of Art, PUC Minas, Brasil

Received: August 2020, Accepted: May 2021

\begin{abstract}
This paper addresses the migration theme as an embodied experience performed by myself in two installation pieces, which serve as examples to explore the notions of displacement and territory in phenomenology and semiotic of culture points of view. A mode of performed narrative within moving images attempts to imagine other existences, through cognition and body studies. Presence and politics in ageless aesthetic forms amplify a performativity experience in body and image, related to Greek Hellenic sites and Brazilian countryside landscapes. How do the visual arts act as both a reenactment of a continuous present through affected sites and a dramaturgy of the moving image, through a migrant body in continuous creation of belonging in unknown lands and seas?
\end{abstract}

Keywords: body; displacement; dramaturgy; visuality; performance

\section{DRAMATURGY OF THE BODY}

From my point of view, as an artist and semiotician, I visit authors and theories which promote a living understanding of our identity as an aspect to be built over a lifetime and memory as a performative way to deal with realities and update both our sense of belonging, as we experience daily exchanges with others and the environment. As a body researcher and video artist, I experiment in two installation works an affective and imagined existence, proposing a performance for displaced bodies.

The goal of this paper is to consider body imaging creation as the dispositive of migrant artists to produce knowledge based on their experiences of migration (in its wide concept), produced, and presented as artworks in their diverse media and aesthetics. For this, important concepts are discussed and two examples are offered as singular experiences of creation of a dramaturgy of displacement, which composes modes of presence and relation to a constant exchange with reality and belonging.

Image as understood by neuroscientist António Damasio (1999) is body-generated ceaselessly in time, in relation to the environment, perception and experience. It disposes of physical properties and gestures. Damasio also tells us about our brain creating images from all our senses, not only sight-image creation being delineated by our sensorial images. Other researchers, such as linguist Mark Johnson (1999), posit that we create images as we move, then generating our own sense of reality.

Body images then become visual and affected within singularities, generating a territory of our own. When a body performs its own subject visuality comes as an impermanent solution. Image creation is a performance of the body, a body event, which embodies in a present moment enunciations and affectations through gestures as sound and image. Body images present very provisory solutions, in simultaneous temporalities and spatialities, becoming visual through a singular dramaturgy.

According to phenomenologist Maurice Merleau-Ponty $(2005,33-4)$, body images would be a set of intentional states that manifest and meet representations in distinct discourses. This comprehension of bodily and visual language extends its movements to performative expression. "The conception of language that transcends our living experience incites us to search beyond the enunciation. [...] Enunciative subjectivity, a narrative event, consists on situation and environment" (2013, 119; 95). From body activities emerge language and image 
creation, which is pointed to by António Damasio, George Lakoff, and Mark Johnson.

The things I experience and feel become images in my body (or mind), and their relation to language operates through levels beyond semantic and semiotic. We can in this context perform discourses in visual forms Narratives of the body are embedded with culture, memory, imagination, and enunciations which recreate a unique vocabulary. The way we communicate thoughts and gestures (as images) acts as a presentation of a state of presence.

Cognitive sciences also offer a powerful understanding of the body in its creation of realities and visual images. To Francisco Varela (1991) cognitive actions are the processes through which body configurations emerge in phenomenological, structural, and evolutional contexts. Cognition acts on corporeal experience, constituted by biological, psychological, societal, and cultural realities as a unity.

Jean-Luc Nancy $(2008,81 ; 121)$ suggests that politics begins and ends with bodies: "no longer a sign, no longer a self, but an anatomy of configurations of the plasticity of what we would call states of body, modes of being and bearing." Visuality would then refers to the image as a situation of the body; it "promotes non-linguistic statements, and possibilities of shared realities." Body narratives as moving images present themselves as a performing procedure is ongoing reality capture.

Tracing Mermaids then is an installation of imagined traces of refuge women who once crossed those lands and left their marked presence. It is me shooting while inhabiting unknown lands in a moving attempt at belonging, addressing rocks, marbles, and roots as engaging (witnessing) characters.

Two performative experiences will be shortly presented as examples of imaging creation with the environment, from an affected and embodied practice of my own: shooting as both a director and a character, in landscapes met in Greece (Kos and Crete islands) and Brasil (Minas Gerais). They both enact a sense of belonging while I make myself create a visual and material presence in the sites themselves, later resulting in two installation pieces of video projections, exhibited in 2018 and 2019: Tracing Mermaids and Body Lands.

\section{PERFORMING NARRATIVES, SITES OF AFFECTION}

Visibility processes, the forms through which we share our experiences and intentions, include inner actions. It is our body that creates space, landscape, and imagination. In image conception-a body performing its subjects, related to perceptions-visuality comes as an embodied solution. Visualities present body states in amplifying performative aspects of aesthetic languages.
As a gesture of body presentation, embodied images are multiplied by their own temporalities, memories, and experiences. Embodied narratives, in the forms of speech, gestuality, and images are presented in a diverse range of media, procedures, and aesthetic solutions in the fields of performativity.

Performance art generally rejects conjunctive, linear narratives, in favour of fragmentary open texts, ${ }^{1}$ strengthening the slippage between signifier and signified. Video images, as a mode of performative body presentation, have the quality to expand a sense of spatiality in its point where body landscapes compose a singular existence. A cartography of experimental narratives, as presented by me as a migrant artist (as myself in the Greek experience), promotes a very diverse range of language connections in a performative practice of imaging capture.

As visual art languages have long evolved in a convergence of media-such as dance, film, sculpture, and installation-in an aesthetic language that best suits each purpose of affected perception, a "migrant gesture" takes place where identity is dissolved into continuous adaptive forms, as creative processes present the environment as a singular site.

Moving images as body images, presented in simultaneous video projections, each with different scenes and sounds, approach the way our body acts, tracing trajectories with undetermined beginnings and endings as a multimedia body. Even though the body is the placeits own site of living-imaging experiences-it is the exchange with the site that enables us to elaborate body discourses evolving any place into a landscape.

To give our images visibility, or to create visualities from our senses, is to trace a singular trail: a trajectory. Trajectories are personalized routes that map our way of thinking. Territories, therefore, can be understood as places where we reinvent ourselves-created from our present intention and trajectory.

Over the last few decades, contemporary art has experienced an increasing complexity of aesthetic languages, forms of exhibition and exposition, and continuous demand for new forms of presentation of a body experience from the refuge, nomadic or migrant ever-changing modes of existence. Art venues face singular cartographies that insist on bringing other ways to visuality to share realities and experiences from migration in its wide conceptions.

Installation art also proposes a place as a site. A theory of sculpture focused on spaciality instead of the object (as suggested by Didi-Huberman), for instance, produces enunciations non-stop, and "acts of place." In audiovisual installations, to conceive an aesthetic form to an embodied narrative involves territories of affectation: our patterns, expectations, affections, in singular forms of presentation. Audiovisual performances, as of

1 The concept of text is here presented in the semiological context, as a set of signs that can be symbolic (verbal), iconic (image), or index (vestiges). 
late art in general, blur not only media specificities but their very production procedures.

Artistic practice has always been in dialogue with contemporary scientific and social evolutions in presentations of realities. Art production helps us think and share knowledge as it attests to multiple reality aspects, bringing powerful understandings of phenomenological studies, from philosophy to aesthetic languages, body politics, and culture. Movement and duration, as both body and image intrinsic qualities, play their parts in ever new enunciations. Medium plays as a singular cartography made by displaced bodies and territories.

To Merleau-Ponty $(2005,35-6)$ the corporeality of language (the "materiality of thinking") is ambiguous: as part of our experience, language would be a faculty of the sensitive world. Corporeality would be articulated on a multiplicity of levels, explains Didi-Huberman $(2013,119)$ : "as a bond between me and things is sensitive experience," that reveals an "inadequacy of ordinary descriptive categories-subject and object, one and other."

Corporeality does not necessarily communicate nor generate instantaneous meanings. This way of being in the world enables us to evolve and relate to other beings in different levels of organization and intention. Presence has often unpredictable configurations in visual arts in general, in the articulation of singular subjects. This quality of artistic work generates enunciations through practices of visibility of embodied imaging production. How may visualities act in environments of our own? Exploring embodied images in aesthetic practices is a creative strategy of a phenomenological body.

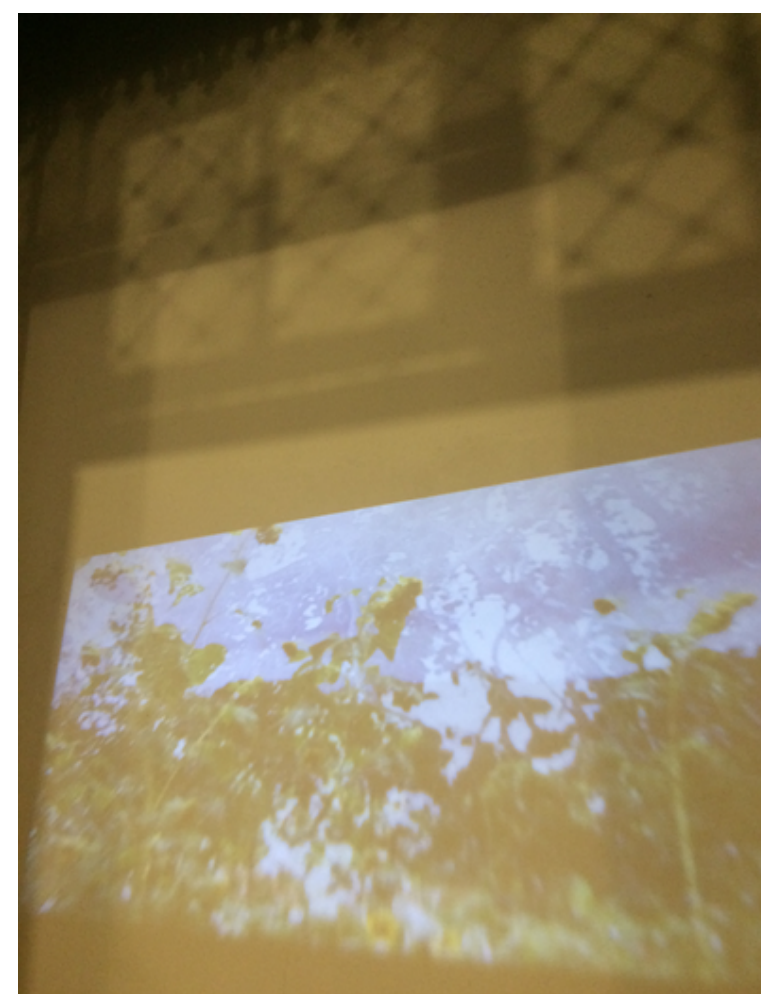

Maurice Blanchot (2011) suggests that language and presence are in inescapable conflict. Subjectivity transforms established knowledge of defined fields as communication, anthropology, history, and social sciences. Convergent works of art act as creative agents of simultaneous fields of study and practice of art-related, meeting in distinct theories close epistemological procedures to engage in body phenomena. Subjectivity promotes "a threshold, without generating a unity" (Greiner 2010, 89); it opens ways to "what survives in action, aesthetic languages that operate in an unpredictable order."

Visibility and visuality operate as key concepts to evolve body aesthetics in installation pieces: a wide range of singularities expressed visually suggest a practice of visibility-of body states, emotions, endurances, thoughts, recreating multiple states of presence through which we perform our selves, in durations and intensities shown, for instance, through the camera and video manipulation possibilities of color, focus, speed, frame, light-as in the two works' examples, Tracing Mermaids and Body Lands.

\section{IMAGINED AND DISPLACED BODIES}

Europe continuously gives shelter to refugees of diverse origins since the last major crisis began in 2015. Migration experiences inspire art and aesthetics through imaginaries of a body dramaturgy able to provide new cartographies and epistemologies. The notions of territoriality and visuality can guide aesthetic narratives, expanding theories of art and human sciences, also providing different ways of approaching body politics.

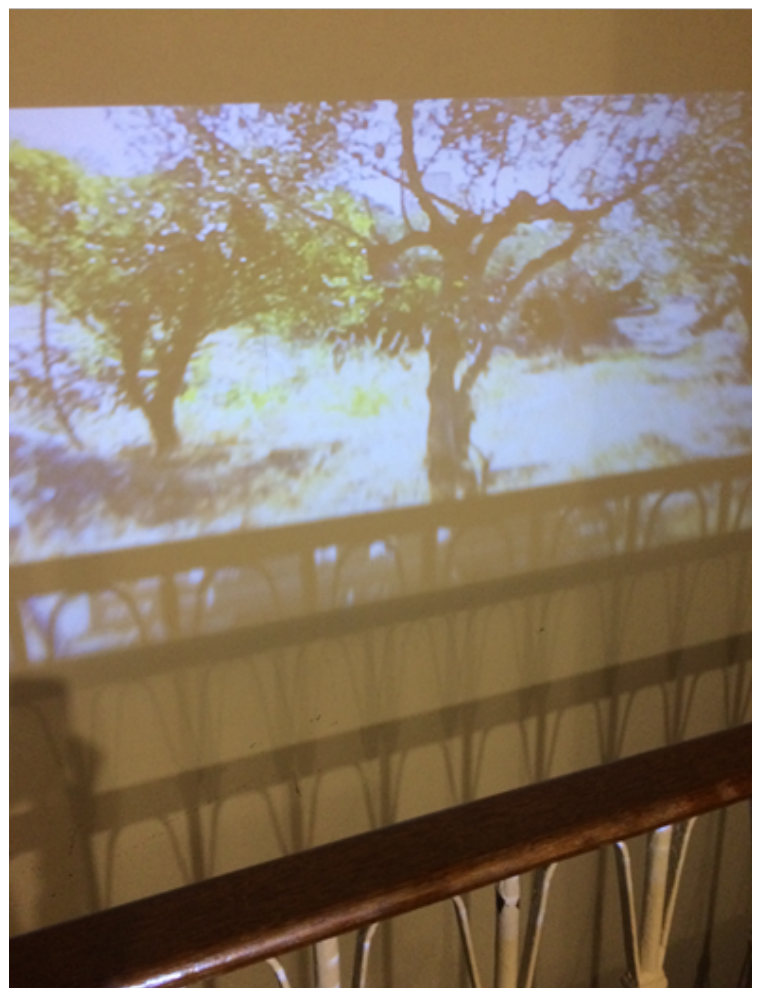

Images 1 and 2: Video installation Body Lands, Monica Toledo Silva, 2019. Adro Gallery (São João del Rei, MG/ Brasil). A result of moving landscapes as collected during a performativity act. 
Being a migrant re-significates one's self, renegotiating pasts and futures in order to embrace new realities, which can act performatively and politically. A displacement embodies contingency, the weight of states of affairs and meanings that beset us with a choice of resingularization. Within one's living memories, the body proceeds in a new territory; the one of the migration of senses to a new set of imaging processing in outer lands.

Migrant narratives displace an art that has imposed itself as normative or official in "Western" cultures for the last three centuries. It also engages a territory where each body has its own dramaturgy. In an ever-affected art experience, embodied images of these nomadic bodies demand a performance of a moving self that continuously negotiates a renewed territory, attesting this performativity of migration. A reenactment of a living practice which transcends space and projects a "here and now" that determines all senses to be present, configuring a new set of being.

Migration art has evolved with humanity and is somehow an ancient topic. What matters to us are the displacements of the very concepts of language and enunciation, provided by diverse enunciations. In a dramaturgy of singular forms, these art languages also demand attention to what is not categorized. An end of oriented references pushes us forward to a practice of landscaping presences of migrant bodies.

Enunciation forms give way to singular landscapes, in new modes of presence made visible. Landscapes are also made visible by intentional actions that create enunciation possibilities. A landscape is then a solution for a state of presence; it enables a sense of being connected to a place. Territories, like trajectories, can then be understood as moving landscapes. To move on a territory adds a sense of affection, rather than a sense of orientation.

Alain Martin (2017) considers art's dynamics of displacement, wherein any moment updates and turns a place into a territory. Territories are places where we recreate ourselves, affected by others' (object and subject) presences and realities. A territory that is not only physical and that also generates meanings, as we are displaced not only in space and we are present not only physically. A territory is made from bodies united in multiple, and simultaneous selves. The nature of agency would then be marked by "diversified and heterogeneous territories" (Foster 2017, 120).

We perform our living experiences embodying territories in landscapes; we belong to territories of affection, activating pasts and futures. Our body evolves as a set of affected experiences to be performed. Narrative diluted to trace is configured as a landscape. Landscape as a dramaturgy of itself, configured as territory.
Displacement, then, is not only space. When a body performs its own subjects into objects of creation, visuality comes as an embodied and impermanent solution. A landscape is also made in a choreographic-rather than cartographic-way as nomad as a body, a vibrant mapping, unplanned. A territory is made with the body, in its latent and inherent tracing cartographies; ${ }^{2}$ it evolves as a moving set of experiences ready to be trailed.

Territory as an appropriation of a place that becomes singular is not only physical and generates meanings. The ideas of territoriality, visibility, and landscape guide artists in their creative procedures, at once expanding and displacing body theories, while providing different ways of approaching material subjects and processes.

The installation Body Lands engages a montage experience, at the exhibition site within the projections, of entrance and transit of visitors "entering" the imagecrossing the landscapes through their silhouettes in the water or sand, performing in the landscape itself. Tracing Mermaids exhibits, differently, objects creating an environment and materializing the images' projections as their extension-dried branches, pearls, little boats, and lost objects compose and produced shadows, also performing the landscape, as placed between the projectors and the images.

Imagined routes based on possible traces of visible marks (old routes, designed rocks, organized sets of trees, ancient history, mapped cultures of nomad peoples, strategic shores and hills, are the creative and affective material from which I worked creating a sense of belonging to the sites while playing a refugee in transit myself.

It is indeed the displacement that generates new mappings and reconfigures a body's dramaturgy. "Enunciative subjectivity, a narrative event, consists on situation and environment" (Didi-Huberman 2013,95). Different modes of perception generate continuous visual solutions. A body filled with temporalities; a deviant media, opened to the impossible exercise of mapping oneself.

\section{LANDSCAPING PRESENCES IN AUDIOVISUAL PERFORMANCES}

According to Félix Guattari $(2011,31 ; 39)$, the multiplicity of expressive enunciation, a multiplicity of active systems, formulate objects of no given meanings. A body also reinvents itself and creates its own meanings (based on how reality is processed in our intentions and active perception); one makes herself present within her own temporalities, experience, and gestures.

Enunciation is taken by the flow of processual creation, "embodied at the intersection of partial utterances on all sides of individual identity" (Guattari 2011, 97). Once language slides between spaces of representation,

2 Brazilian Suely Rolnik will add that cartographies are constituted by cultural and artistic "micro universes," where relations are empowered and gain sense and value. These cartographies, "cinematographic, theatrical [...], of a sensitive place, are disposed to the collective affected by this place, as guides that help to circulate through their unknown landscapes" $(1997,3)$. 
performance is also an anthropological term that relates to the conditions of experience, referring to a point in time that is experienced as present. Performative acts also constitute reality and generate the culturally and historically marked body.

A place belongs to the body, it exists in the body, as a culture-we bring our own culture and landscapes along wherever we go. To belong somewhere is to belong to itself: the body. Guattari $(2011,78)$ proposes a "reterritorialization activity," essentially an embodied intervention, affective and affected, that would "territorialize assemblages of enunciation." A territory is an embodied appropriation of a place that becomes singular and performed. A territory that is not only physical, as a presence is placed in what is preserved.

Affected memory reviewed and embraced new imaginaries or possibilities of embodiment from a new time in a familiar place; original spaciality within my intentional presence with a camera in performative practice. Enunciations, as minimal unities and undefined interchangeable forms of discourse, are displaced. Didi-Huberman (2013, $25 ; 79)$ considers that discursive formations "are not limited to a language reality" and would correspond to one or many regimes of visibility. Visual, gestural, and sound enunciations are living materials from which this nature of artistic work, based on self experiences (such as migration). Migration as an experience working source assumes a dynamic set of singularities in the image-production process.

Aesthetic images amplify aspects of performance, exploring visuality as a gesture of body presentation.
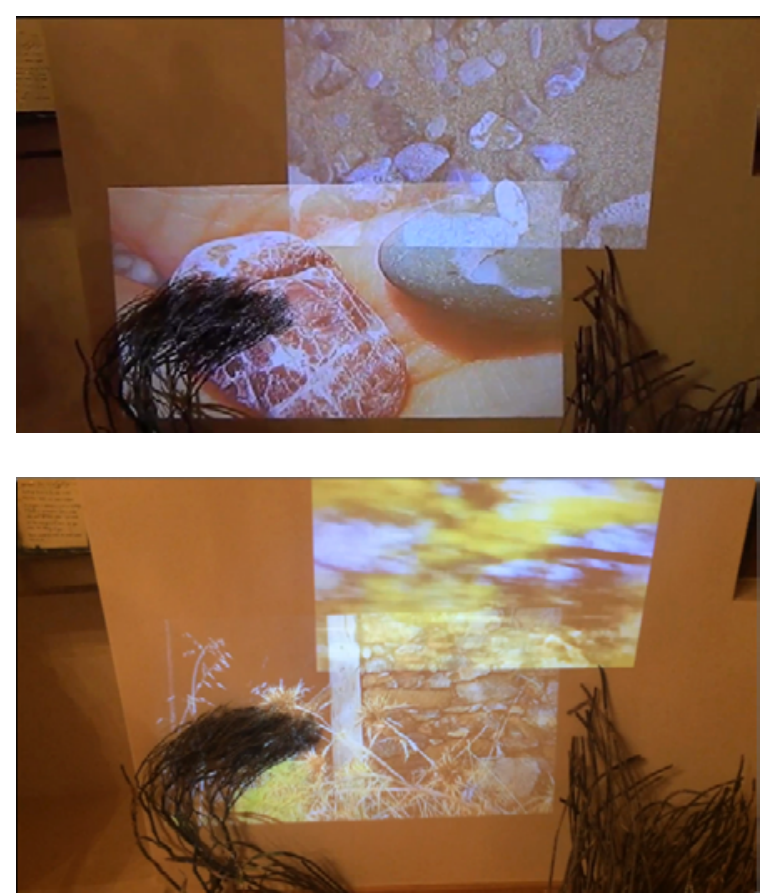

Images 3 and 4: Video installation Tracing Mermaids, Monica Toledo Silva, 2018. Mudhouse Art Residence (Greece). A search for women refugees in the Greek islands of Crete and Kos, recreating their trajectories, and presences.
Art production helps us to think and share realities as it attests to life in its diverse aspects. This nature of image-making, based on intention and perception, takes place while creating a dynamic form that makes sense to the body, in relation to its memories and own subjects.

As potent signifiers move through a perceptive environment, what makes sense is the very possibility of unrest of the sign related to body awareness; even in a resting state, our images are fulfilled with pauses and losses, in a moving condition where each sensorial gesture is never repeated. Through this performative understanding of our affected bodies, I experience sights and sounds as an extension of my body which acts in this spatial-temporal context.

To live exceeds planned procedures: a territory is made with the body, in its latent living cartographies. Our body evolves as a set of moving experiences, to be traced when performative acts are in play. The subjectivity of the concepts of frontier (being both personal and political), territory (landmarked and also made from affection), nomadism (as natural for the moving body even if it "belongs" somewhere), carries the shifts of a migrant body-deviant, although intentional. A body that can only be mapped through impressions from the site (as hybrid times and places) in a present state (which then specifies duration and intensity).

A dramaturgy of images displaces the notions of territory (as situated) and refuge (as nomad) once it proposes to reinvent space through presence. The inspirations of the use of these terms come from its contemporaneity in the geopolitical global context of massive refugee migrations, while we experience an unbound of their meanings when addressing the living body and its living narratives.

How have human and visual landscapes evolved with migrant artistic practices? A dramaturgy of images becomes visual with its performative engagement at singular levels. Singular corporealities explore both live and virtual modes of presentation. The understanding of cartography as a performance generated by a body spatiality is related to migration as an enunciative form itself; to map a nomad path. A migrant body will be both a historical-political one in search of a new home, and the artist who connects his practice and creative existence with the understanding of place as a performative scenery, to be fulfilled, embraced, signified, occupied, by his modes of presence and imaging performativity.

A dramaturgy of the image becomes what evolves, not what remains. A sense of reality based on sets of singular patterns performs a body landscape. To embody a landscape is to inhabit a time and a space created in the present, in which an embodied image is performed. A dramaturgy in these senses would be a trajectory through territories marked by presences which create landscapes. When a body performs its own subjects into objects of perception, visuality comes embodied: according to Jean-Luc Nancy (2008), it's a question of what, in language, no longer involves the message, just its inscription. 
Migrant images: aesthetic imagination in experiences of displacement

\section{REFERENCES}

Blanchot, M., 2011[1955]. O espaço literário. Rio de Janeiro: Rocco. Damasio, A., 1999. O misterio da consciência. São Paulo: Companhia das Letras.

Didi-Huberman, G., 2013[1953]. O que vemos, o que nos olha. São Paulo: Editora 34.

Fischer-Lichte, E., 2008 [2004]. The transformative power of performance. A new aesthetics. Rutledge. Foster, H., 2017[2011]. O complexo arte-arquitetura. São Paulo: Ubu.

Greiner, Ch., 2010. O corpo em crise. São Paulo: Annablume. Guattari, F., 2011[1989]. As três ecologias. Campinas: Papirus. Lakoff, G., Johnson, M., 1999. Philosophy in the flesh, the embodied mind and its challenge to western thought. New York: Basic Books. Massumi, B., 1995. The autonomy of affect. University of Minnesota Press: Cultural Critique, n31.
Merleau-Ponty, M., 2005[1964]. Le Visible et l'invisible. Claude Lefort (Ed.). Paris: Gallimard.

Nancy, J., 2008. Corpus. Fordman University. Rolnik, S. 1997. Uma insolita viagem à subjetividade Fronteiras com a tica e a cultura São Paulo: Núcleo de Estudos da Subjetividade, PUC SP.

Silva, M. T., 2021 (to be published). Body lands: image performativity in object and shadow. Athens: Academic Journals Humanities \& Arts. Athens Institute for Education \& Research.

Spackman, H., 2000. Minding the matter of representation: staging the body (politic). in Campbell, Patrick. The body in performance. Contemporary Theatre Review. International Journal v. 10 part 3.

Varela, F. J., Thompson, E., Rosch, E., 1991. The embodied mind: cognitive science and human experience. London: MIT Press. 